Anuário de Literatura

Volume 15

Número 02

\title{
O GLOBAL E O INSULAR: A DIMENSÃO DO ESPAÇO EM SARDINIA BLUES
}

Ana Maria Chiarini Doutora em Estudos Linguísticos e Professora Adjunta - UFMG

Diego Silveira Coelho Ferreira Graduando em Ciências Sociais - UFMG 


\section{GLOBAL AND INSULAR DIMENSIONS: SPACE IN SARDINIA BLUES}

RESUMO: Este trabalho se propõe a analisar o romance Sardinia Blues, de Flavio Soriga (Bompiani, 2008), a partir do foco no espaço, perspectiva esta que se justifica pela centralidade da dimensão espacial na obra desde o próprio título. A Sardenha do romance apresenta-se não apenas como cenário, mas como fio condutor e articulador de temáticas que dizem respeito à própria condição identitária e existencial dos personagens. As relações com o espaço regional sardo, percebido como folclorizado e estereotipado, e as relações com o espaço global, ao mesmo tempo fonte de medo e desejo, são problematizadas durante as longas horas de ócio de três jovens, que se autodenominam "piratas" da ilha. Pretendemos evidenciar os conflitos dessa condição insular marginal, mas fortemente contaminada por um inevitável processo de mudança, que se configura no texto fragmentado de Soriga, repleto de citações musicais e híbrido de várias línguas, tanto inovador quanto nostálgico.

PALAVRAS-CHAVE: espaço; globalização; literatura italiana contemporânea

ABSTRACT: The aim of this work is to focus attention on the dimension of space in Sardinia Blues (Publisher Bompiani, 2008), by Flavio Soriga. This is justified by the centrality of space throughout the novel and by the title itself. The island of Sardinia is not just a mere setting, but it is most importantly the articulating and conducting thread for all the themes related to the characters' self-identity and existential issues. The regional Sardinian space, perceived as stereotyped and folkloristic, and the global space, seen as a source of both desire and fear, are problematized by the three young self-proclaimed "pirates of the island" in their long hours of idleness. It is our intention to highlight the conflicts of this marginal insular condition, heavily contaminated by an inevitable process of change, in Soriga's simultaneously innovative and nostalgic fragmented text, filled with songs' extracts and languages hybrids.

KEYWORDS: space; globalization; contemporary Italian literature 
Sardinia Blues, de Flavio Soriga, jovem escritor italiano da última década, narra as aventuras de três rapazes desempregados, devidamente munidos de diplomas de graduação e pós-graduação, num tórrido verão da Sardenha contemporânea. O tédio e o ócio pautam a vida dos amigos - Pani, Corda e Licheri e encorajam pequenos golpes de ladrões de província, noitadas e perambulações por estradas e bares da região, bem como longas conversas, tão amargas quanto divertidas, sobre a própria condição insular. Corda, aspirante ao sucesso literário, resume a contradição que domina os três personagens ao discursar bêbado, no salão da prefeitura da cidadezinha de San Gavino, durante a cerimônia de premiação de um concurso de contos, no qual obteve o segundo lugar. Desabafa Corda:

[...] se eu fosse um jovem escritor sem sucesso norteamericano poderia ao menos esperar me tornar um dia um escritor de sucesso norte-americano[...] no entanto, sou apenas um autor falido sardo, e se viesse a escrever e publicar um grande livro [...], de toda forma, caros senhores, me transformaria num escritor de sucesso sardo, e então minha sorte seria ainda pior do que a atual, pois deveria percorrer os prêmios literários italianos diante de uma platéia triste como a desta noite, deveria falar dos montes e dos bandidos e dos queijos e dos pastores e dos carabinieri e [...] das botas e das tradições milenares e da natureza incontaminada e das praias cristalinas e [...]de todos esses trastes malditos que nos atormentam e nos sufocam há cento e cinquenta anos [...] eu seria apontado à nação boquiaberta como o incrível nativo da ilha da Sardenha que sabe ler e escrever, o enésimo narrador de uma terra inenarrável, de um mundo arcaico e fascinante fora do mundo e da modernidade, meu Deus ${ }^{1}$

Corda é certamente um entre os inúmeros escritores que se rebelaram contra a árdua tarefa de escrever sob a marca redutiva da própria origem geográfica. Machado de Assis, por exemplo, no debate com o movimento nativista, já sustenta peremptório que " $[\mathrm{u}] \mathrm{m}$ poeta não é nacional só porque insere nos seus versos muitos nomes de flores ou aves do país" e lembra Shakespeare para defender sua posição, perguntando-se "se o Hamlet, o Otelo, [...] a Julieta e Romeu têm alguma coisa com a história inglesa [...], e se entretanto, Shakespeare não é, além de um gênio universal, um poeta essencialmente inglês" ${ }^{2}$. Jorge Luis Borges, do alto de seu êxito literário, também parece compartilhar da posição do falido Corda, ao comentar que no Alcorão, o livro mais árabe entre todos os livros, não há camelos:

[...] um falsário, um turista, um nacionalista árabe, a primeira coisa que teria feito é prodigar camelos, caravanas de camelos em cada página; mas Maomé, enquanto árabe, estava tranquilo: sabia que poderia ser árabe sem camelos. ${ }^{3}$

Seguindo o percurso proposto num ensaio de Silviano Santiago, de onde extraímos as palavras de Machado e de Borges, encontramos os modernistas diante da mesma áspera questão, reagindo, porém, de maneira diversa dos escritores citados. Se o irrequieto Corda decidisse visitá-lo na São Paulo dos anos 20, Mário de Andrade

\footnotetext{
1 SORIGA, 2008, p.122. Tradução nossa. Esse será o caso sempre que a referência bibliográfica constar em outra língua.

${ }^{2}$ MACHADO DE ASSIS, Joaquim Maria, apud SANTIAGO, 2004, p.18.

${ }^{3}$ BORGES, Jorge Luis, apud SANTIAGO, 2004, p.43.
} 
decerto o aconselharia, com bom humor, a tratar, sim, de "todos esses trastes malditos" a que se refere o aspirante a escritor, pois apenas sendo primeiramente sardo e fazendo as contas com o próprio passado - isto é, com queijos e botas e pastores - é possível ser universal. Mas e se fosse o intelectual paulistano o privilegiado hóspede de Corda na linda Sardenha de hoje, quando o nacional parece ter sofrido abalos e os fluxos globais impõem-se agressivos, enredando até pontos isolados do planeta? Qual seria seu conselho ao novato?

Há que se diga que Sardinia Blues não é um romance sobre escrever literatura num espaço periférico da contemporaneidade, mas um romance sobre viver a juventude num espaço periférico da contemporaneidade. Decidimos iniciar o texto expondo os dramas e conflitos do jovem escritor porque estes traduzem os dramas e conflitos comuns aos três amigos, os quais se indagam sobre o peso da Sardenha natal que carregam nos ombros, numa era supostamente marcada pela solidez que evapora no ar, pela velocidade e leveza da circulação de bens e da informação. "Estamos falando de um tempo onde a pergunta sobre o lugar, ou melhor, sobre o que resta do lugar, é a chave" " Assim se pronuncia Jesús-Martín Barbero discorrendo acerca do presente, e é em busca de tal chave que se movem os autodenominados "piratas" da ilha - personagens inquietos, vocacionados para o trânsito e saqueadores de significados culturais por excelência. O que resta do lugar em que residem? Em que se transforma? Como interagir com esse espaço que não é o espaço folclorizado e anacrônico, que não é o espaço do turismo exclusivo de luxo, mas que é tudo isso de algum modo? Como interagir com uma Sardenha que não é Londres nem Barcelona, cidades onde habita o sonho sardo quando o jovem sardo

\footnotetext{
${ }^{4}$ OSSA, 1998, p.11.
}

nelas não habita, e que "todavia é um paraíso [...] se se resiste aos meses de inverno frio, se não se suicida de tédio em fevereiro" ${ }^{5}$ ?

Milton Santos nos ensina que "[o] espaço é igual à paisagem mais a vida nela existente; é a sociedade encaixada na paisagem, a vida que palpita conjuntamente com a materialidade" 6 . Cabe notar que na narrativa ansiosa de Soriga, em parágrafos quase privos de pontos, escutamos a vida palpitando também fora dali, atraída por apelos globais e promessas de outras trajetórias, e enxergamos a ilha se alargando, se abrindo, em especial no plano dos sonhos. Nesse sentido, para seus jovens, o espaço da Sardenha tanto supera a paisagem insular, através de trânsitos culturais e afetivos voltados para o exterior, quanto se impõe asfixiante e restritivo a vôos, desejos e aspirações. "O espaço é formado de fixos e fluxos" 7 diz ainda o mestre geógrafo -, num descompasso de proporções consideráveis acrescentaríamos nós, fazendo eco aos piratas, descontentes com o desequilíbrio entre os chamados dos tráfegos e os constrangimentos da fixidez.

A maioria dos pensadores da pós-modernidade evidencia o caráter transterritorial, multilinguístico e híbrido das identidades contemporâneas, embora o maior ou menor peso que se dá ao Estado nacional permaneça um ponto polêmico. No caso do romance, há raras referências às relações com a nação italiana: o foco incide sobre a Sardenha e o mundo, bem como sobre as conexões - insatisfatórias, segundo os personagens - entre ambos. Isso posto, convém notar que o blues, central já no título, é acionado exatamente pelo que essa escassez de conexões promete ou deixa entrever, e instaura-se resoluto pois a porção de terra cercada de água por

\footnotetext{
${ }^{5}$ SORIGA, 2008, p.32.

${ }^{6}$ SANTOS, 2008, p.85.

${ }^{7}$ SANTOS, 2008, p.85.
} 
todos os lados, deslocada do resto do planeta, opõe resistência à concretização do trans, do multi e do híbrido, ainda que não impeça a fruição dos prazeres.

- Nós -, diz Licheri, - Nós somos já de cara derrotados por essas paranóias identitárias e antiidentitárias e não se escapa, nesta ilha maldita, do mal de ser insular [...]- Nós temos que nos livrar dos fantasmas da história, dos nossos imensos atordoantes complexos de inferioridade e de marginalidade e de perifericidade, aceitar que somos como os outros, todos os outros, nem melhores nem piores, excelentes homens quaisquer do mundo, é essa a revolução que nos cabe fazer mais cedo ou mais tarde [...]- Como é lindo o verão [...] - Como são lindas as noites de julho $-^{8}$

Assim, nesse contexto, a Sardenha dos três amigos é apresentada ao leitor como um peso do qual se devem liberar, mas ao qual se mantém ligados tanto pelos limites impostos pelas próprias condições materiais de vida quanto pela beleza incomparável da paisagem, certamente povoada de afetos.

García Canclini, em seu Consumidores y ciudadanos, defende que, em tempos de globalização, enquanto debilitam-se os antigos arraigamentos territoriais, as identidades se estruturam muito mais sob a lógica dos mercados do que dos Estados e se configuram a partir do que se possui, do que é possível vir a se apropriar e da comunicação estabelecida para que tal apropriação se efetive. Ser cidadão não mais remete a direitos e deveres reconhecidos por aparatos estatais, mas a práticas sociais e culturais que definem pertencimentos e alianças construídos a partir da circulação global de bens e informações. Configuram-se os iguais e os diferentes, promove-se a integração e estabelecem-se distinções, através do consumo de objetos e símbolos, apesar das fronteiras físicas.

Licheri, que discursa sempre e nada em hipérboles, ilumina a importância de tais objetos como ícones identitários pós-modernos quando narra aos companheiros seu choque diante da opinião de uma namorada sobre suas velhas botas alemãs.

[...] eu estava ali calçando, essa menina viajada me olhou e disse Você não vai querer usar essa coisa, vai?, [...] Parece com as botas dos pastores daqui de Busàchi, ela me disse com sua voz sem sotaque de ex-estudante Erasmus e apátrida entusiasmada -

- Vocês estão entendendo?! [...]Os meus coturnos fabricados na Alemanha e calçados por milhões de jovens de todas as nações do mundo[...]Você está parecendo um pastor, ela disse, pra mim!, pro cantor pós-moderno da estética sem raízes, pra mim!, impávido defensor da desestruturação dos pertencimentos ${ }^{9}$

$\mathrm{Na}$ tessitura da rede de referências compartilhadas e de comunidades globais por onde transitam os piratas, em meio a botas alemãs, mojitos consumidos no Peyote disco club e menções a Hasta siempre Comandante, dentre centenas de citações musicais, um produto ou laço chama atenção: o sangue. Pani, o narrador, define-se 
"um doente crônico, por assim dizer, um sobrevivente" ${ }^{10}$ : é talassêmico e, desde o nascimento, a cada quinze ou vinte dias, esteja onde estiver, é obrigado a se submeter a transfusões. De acordo com suas palavras, "a encher o tanque, seiscentos gramas de sangue de generosos desconhecidos de quiçá qual etnia ou credo ou classe social ou religião" ${ }^{11}$. Assim, apresenta-nos uma galeria de pessoas conhecidas nos corredores de hospitais, em especial de um localizado na periferia londrina, onde viveu; lembra-se de quando, menino, se descobre "irmão de sangue" 12 de um roqueiro bêbado australiano e enfatiza as semelhanças além das fronteiras.

E eu ficava ali três horas fazendo a transfusão e tentava escutar música com os fones nos ouvidos [...]

E havia os talassêmicos filhos de turcos que folheavam suas revistas de automóveis [...], exatamente como fazem em Cagliari os talassêmicos de Gúspini

E havia as talassêmicas filhas de cipriotas que folheavam suas revistas de fofocas sobre celebridades da $\mathrm{TV}$, exatamente como fazem em Cagliari as talassêmicas de Villacidro $^{13}$

Parece-nos significativo que, em Sardinia Blues, seguindo o raciocínio de García Canclini, seja um determinado tipo de consumo - o consumo de sangue, nada menos que isso - a atuar de maneira efetiva em função da racionalidade integrativa e comunicativa do indivíduo. Dito de outro modo, é o consumo de sangue, mais que qualquer outro tipo de relação extra-ilha, que vem ao encontro do anseio de

\footnotetext{
${ }^{10}$ SORIGA, 2008, p.89.

${ }^{11}$ SORIGA, 2008, p.88.

${ }^{12}$ SORIGA, 2008, p.115.

${ }^{13}$ SORIGA, 2008, p.128.
}

comunidade expresso por um dos piratas pós-modernos. Pani estabelece relações fundamentais em sua vida, estimulado por uma necessidade - que também se configura como desejo - ligada a uma substância elementar, da ordem da natureza, ou movido por uma dependência indiscutível da disponibilidade generosa da humanidade em doar.

Como podemos interpretar isso? Como otimismo do romance? A integração global é viável, já somos unidos e o mundo está aqui, na Sardenha ou em Nova York? Ou como afirmação da prioridade absoluta dessa integração, ainda longe de se concretizar, para os periféricos, para os deslocados do planeta e para a espécie humana? Nossa interpretação do romance não aposta na alternativa mais rósea.

De fato, a talassemia é uma doença de grande incidência no Mediterrâneo e remete ao isolamento geográfico dos povos da região. Nesse sentido, Pani é um porta-voz da Sardenha originária de um mesmo sangue, doentio em sua identidade, e carente da diversidade, tanto cultural quanto biológica, renovadora. A doença apresenta-se como sintoma da insularidade identitária sarda, ao mesmo tempo em que aponta para o desejo e a necessidade da troca, revelando, quem sabe, a aporia que reveste a contemporaneidade da ilha.

Grínor Rojo de la Rosa, em Globalización e identidades nacionales y postnacionales... de qué estamos hablando?, critica duramente García Canclini e a "dócil funcionalidade"14 do contexto global em que seu cidadão consumidor está inserido. Para Rojo de la Rosa, Canclini desenha um cenário em que bens e serviços gerados por um sistema com inúmeros centros seriam consumidos e intercambiados de maneira homogênea e consensual, em que o poder se dissolve no múltiplo, perde nome e sobrenome, e exclui o conflito, ou ainda, em que uma identidade particular -

$\overline{{ }^{14} \text { ROJO DE LA ROSA, 2006, p.79. }}$ 
aquela da sociedade capitalista - é generalizada em escala macro. Poderíamos afirmar que, em consonância com o blues dos piratas, o crítico chileno rechaça com veemência a ideia do antropólogo argentino de que "agora o mundo todo está aqui e é difícil saber o que é próprio" ${ }^{15}$.

$\mathrm{Na}$ Sardenha babélica de Soriga, em que pesem as inúmeras referências cosmopolitas e o desfile de ícones internacionais, o consumo de símbolos não basta para que alguém se torne cidadão do mundo e seja tratado enquanto tal. O mundo não está todo aqui, não é o mesmo em todo lugar, e talvez seja a consciência dessa negação a estimular o desassossego, o abuso do álcool e da ironia, e a vontade de viver no limite do trio de amigos. Paralelamente, é preciso que se diga, a vida ociosa, sem uma ação transformadora da região que habitam, tampouco permite que os jovens criem vínculos mais profundos, de cidadão, com o próprio espaço, pois se quebra a relação homem-espaço-sociedade, mediada pelo trabalho, como propõe Milton Santos.

Assim, Sardinia Blues, desde o hibridismo linguístico do título, apresenta-se para nós como um lamento melancólico que embala a celebração de uma terra percebida como absurda pelos três personagens. A despeito da avidez típica da juventude ou a despeito do ritmo frenético, impresso nos parágrafos curtos e sem pontos, que destoam do blues e da modorra do lugar, o romance exala um intenso amor, jamais explicitado em palavras, a uma realidade inexoravelmente fadada à mudança ou ao desaparecimento. Reivindica-se o novo, lamenta-se a atemporalidade estática da vida de província - “ar, ar, ar, longe daqui”, ${ }^{16}$, suplica Pani - mas, num paradoxo, teme-se o futuro incerto. Dança-se ao som de música eletrônica, entoam-

\footnotetext{
${ }^{15}$ GARCÍA CANCLINI, 1995, p.79.

${ }^{16}$ SORIGA, 2008, p.75.
}

se canções em inglês e espanhol - já que "a Sardenha é o nosso México" 17 " "Sassari, nossa pequena decadente Buenos Aires" 18 e "Cagliari, nossa pequena cintilante Los Angeles" 19 . Morre-se pelas balas sibilantes de um mercenário ciumento regressado do Iraque, porém, não é difícil imaginar que se pranteie o morto, num coro trágico, em bom sardo.

È curioso que, em tempos de modernidade líquida, de capitalismo financeiro e riquezas geradas pela mágica das tecnologias da informação, o capital e os poderosos movimentem-se leves, quase invisíveis, numa dimensão espacial fluida e sem peso, segundo Zygmunt Bauman, enquanto os três companheiros de Soriga, não tão nômades quanto gostariam, não tão globais quanto o desejado, veem-se obrigados a acertar as contas com o próprio espaço. Para o sociólogo, quem manda hoje são "os mais escapadiços, os que são livres para se mover de modo imperceptível" 20 , são aqueles que podem decidir sobre a própria capacidade de fugir, de se desengajar, de estar em outro lugar, e que, ao mesmo tempo, tolhem, limitam ou retardam os movimentos daqueles que obedecem. De um lado, portanto, sempre os barões - barões a saltar nas árvores -, do outro, entre os servos da gleba, aqueles coagidos à imobilidade, tal qual os jovens piratas sedentos de mundo.

\footnotetext{
${ }^{17}$ SORIGA, 2008, p.9.

${ }^{18}$ SORIGA, 2008, p.13.

${ }^{19}$ SORIGA, 2008, p.13.

${ }^{20}$ BAUMAN, 2001, p.140.
} 


\section{REFERENCIAS}

BAUMAN, Zygmunt. Modernidade Líquida. Trad. Plínio Dentzien. Rio de Janeiro: Jorge Zahar, 2001.

\section{GARCÍA CANCLINI, Néstor. Consumidores y ciudadanos. Conflictos}

multiculturales de la globalización. Miguel Hidalgo, México, D.F.: Editorial

Grijalbo, 1995.

OSSA, Carlos. Destiempos culturales, fragmentaciones latinoamericanas y resíduos utópicos (una entrevista con Jesús Martín-Barbero). Revista de Crítica Cultural, no. $16,1998$.

\section{ROJO DE LA ROSA, Grínor. Globalización e identidades nacionales y}

postnacionales... de qué estamos hablando? Santiago: LOM Ediciones, 2006.

SANTIAGO, Silviano. Atração do mundo. Políticas de globalização e de identidade na moderna cultura brasileira. In Santiago, S. O cosmopolitismo do pobre. Crítica literária e crítica cultura. Belo Horizonte: Editora UFMG, 2004.

SANTOS, Milton. Metamorfoses do espaço habitado: Fundamentos Teóricos e Metodológicos da Geografia. Milton Santos; em colaboração com Denise Elias. São Paulo: Editora da Universidade de São Paulo, 2008.

SORIGA, Flavio. Sardinia Blues. Milano: Bompiani, 2008. 